\title{
Diversity and Community Assemblage of Littoral Zone Benthic Macroinvertebrates in Jagadishpur Reservoir
}

\author{
${ }^{1}$ Deep N. Shah, ${ }^{1}$ Ram D. Tachamo Shah and ${ }^{2}$ Bandana K Pradhan \\ ${ }^{1}$ Hindu Kush Himalayan Benthological Society, Kathmandu \\ ${ }^{2}$ Department of Community Medicine and Family Health, Institute of Medicine, Tribhuvan University \\ e-mail: deepnarayanshah@hkhbenso.org
}

\begin{abstract}
Littoral benthic macroinvertebrates diversity and community assemblage of Jagadishpur Reservoir were studied during post-monsoon (2008) and pre-monsoon (2009) seasons. Altogether twelve sites in the littoral zone of the reservoir were sampled for benthic macroinvertebrates by using a kick-and-sweep method with a standard handnet. At each site, benthic macroinvertebrate samples were taken from different possible substrate types. The environmental variables of each site were collected based on Lentic Ecosystem Field Protocol during sampling. Biological metrics were used to describe the diversity and composition of benthic macroinvertebrates. The relationship between benthic macroinvertebrates assemblage and substrate types were examined by using principal component analysis. Cluster analyses were performed to describe the similarity among samples. In total, 50 taxa, belonging to 15 orders were recorded for littoral zone of the reservoir. The recorded higher number of taxa (family level) belonged to order Heteroptera (water bugs) and Diptera (flies), and class Mollusca. Mollusca for post-monsoon and Diptera (particularly Chironomidae) for pre-monsoon shared the highest proportion in the total density. Shannon diversity index $\left(\mathrm{H}^{\prime}\right)$ for post-monsoon was $1.82 \pm 0.46$ and for pre-monsoon was $1.38 \pm 0.53$ and was significantly different between seasons $(\mathrm{p}=0.01)$. Principal component analysis revealed that increase in taxa numbers were positively correlated to soft substrates while negatively correlated to non-soft substrates in littoral zone of the reservoir. Cluster analyses discriminated the sites into two main groups for both seasons. The study concludes that benthic macroinvertebrates diversity is highly influenced by substrate types, water level fluctuation, and human accessibility to the reservoir. Therefore, in order to stabilize benthic macroinvertebrates diversity and their abundance, it is essential to maintain surface water level, stabilize bank substrate and minimize human pressure.
\end{abstract}

Key words: benthic macroinvertebrates, aquatic biodiversity, littoral zone, reservoir, substrates

\section{Introduction}

The ecological attributes of wetlands (rivers, lakes, reservoir, marshy lands, paddy fields etc) are highly diverse and provide especially important ecosystem services (Costanza et al. 1991). These valued ecological attributes, such as water storage capacity, biogeochemical cycling, biotic productivity, and biodiversity, are integral to the structure and function of wetland ecosystems and their ecological integrity (Stevenson \& Hauer 2002).

Benthic macroinvertebrates (BMI) play an essential role in key processes (food chain dynamics, 
productivity, nutrient cycling and decomposition) within wetland ecosystems (Batzer et al. 1993, Hann 1991, Reice \& Wohlenberg 1993, Schriver et al. 1995). For example, many fish and waterfowl species depend on BMI communities for food (Wiley et al. 1984, Euliss \& Grodhaus 1987; Swanson 1988, Euliss et al. 1991). They also indicate any environmental changes like eutrophication and several other modes of lake degradation which are reflected by related changes in their structure (abundance and species composition) (Solimini et al. 2006, Sharma \& Rawat 2009). Hydrological and morphological alterations cause the most severe impact on littoral BMI structures since their low mobility restricts their ability to follow the receding water than fish, and exhibit a much higher dependence on littoral habitat types (Solimini et al. 2006). The water level fluctuations reduce diversity and alter the composition of littoral habitats (Baxter 1977; Hellsten et al. 1996; Hill and Keddy 1992; Solimini et al. 2006) which may affect littoral species composition. In such system, macrophytes play important role by providing attachment sites and materials to build protective retreats to invertebrates (Soszka 1975, Lodge 1985, Dudley 1988). Biological metrics such as species richness, diversity, and composition measures are often used to describe ecological changes of an ecosystem (e.g., Niemi \& McDonald 2004, Shah et al. 2011) as they integrate the effects of multiple stressors, including those whose mechanisms or even existence might be poorly known.

Jagadispur reservoir is one of the most important wetlands of Nepal designated as Ramsar site in 2003 and is also highlighted in the Directory of Asian Wetlands chiefly because of its support for threatened and endangered species of birds and mammals. A total of 118 bird species are recorded from the reservoir in which seven species are globally Threatened and three species are Near Threatened (Baral 2008). The globally Threatened smooth-coated Otter (Lutrogale perspicillata) also occurs in the reservoir area (DNPWC \& IUCN 2003 cited in Baral 2008). Nearly 2000 people live in the immediate vicinity of the lake within $500 \mathrm{~m}$ radius. The majority of people living in the area are from Tharu, Yadav and Muslim communities. There are also migrated hill tribes eg. Brahmin, Chhetris, Gurungs, Magars, etc. Majority of villagers that live in the adjacent area are farmers and are poor.
The reservoir was built in the early 1970s over Jakhira Lake and agricultural land for irrigation purpose. Currently, it supplies water for 6,200 ha of surrounding cultivated lands for irrigation (Fact sheet of Nepal 2005). It also provides tremendous economic benefits to local people, for example, fisheries; maintenance of water table and nutrient retention in surrounding wetlands; timber production; energy resources (fuelwood and fodder collection), domestic use (e.g. laundry), harvesting of wetland products (e.g. Gastropods-apple snails, macrophytes-waterchestnut), recreation (e.g. picnic spots, bathing) and tourism opportunities.

The reservoir water is extensively used by local farmers during crop seasons. Although, the reservoir gets replenished from the Banganga river, the water level fluctuates remarkably from dry to wet seasons. The water level becomes very low during pre-monsoon and only covers its bottom which is mainly composed of soft substrates like mud, organic debris. In contract, the water level is relatively higher during postmonsoon and reaches up to its dike which is composed of non-soft substrates like boulders, cobbles and stones. Additionally, it is subjected to various human use e.g. fishing, grazing, fuel wood and fodder collection, domestic use (e.g. laundry), harvesting of wetland products, recreation (e.g. picnic, bathing, boating) and supply of water for irrigation.

There have been some studies focused on assessment of water quality (Gautam and Bhatarai 2010) and birds' status (Baral 2008). However, the diversity and structure of littoral benthic macroinvertebrates are still poorly known from the reservoir though it has high significance in understanding the overall status of the ecosystem. Thus, the present research focuses on diversity and community assemblage of benthic macroinvertebrates and their relation to stressors of the reservoir for post-monsoon (2008) and premonsoon (2009) seasons.

\section{Methodology Study area}

Jagadishpur Reservoir (also known as Sagar Taal), located at $27^{\circ} 35^{\prime} 00^{\prime \prime} \mathrm{N}$ and $83^{\circ} 05^{\prime} 00^{\prime \prime} \mathrm{E}$ (altitude 197m) in Taulihawa county, Kapilbastu district, is the largest (157 ha) manmade reservoir in Nepal (Fig. 1) with a total shoreline perimeter of approximately $5 \mathrm{~km}$ (Bhuju 
et al. 2007). The average depth of the reservoir is $3 \mathrm{~m}$. The eastern part of the reservoir has shallow water body whereas the western part is deeper. Marsh meadows and extensive mudflat fringed by marsh lies in the northern part. The reservoir is surrounded by cultivated land and few smaller lakes. It is fed by Banganga River which exhibits a large catchment in the Churia hills.

The reservoir banks are paved with boulders, cobbles and stones. Dalbergia sisoo (sisoo) and Acacia catechu (khair) are dominated trees along the dyke. Since 2007, commercial fish farming has started in the reservoir by contractors.

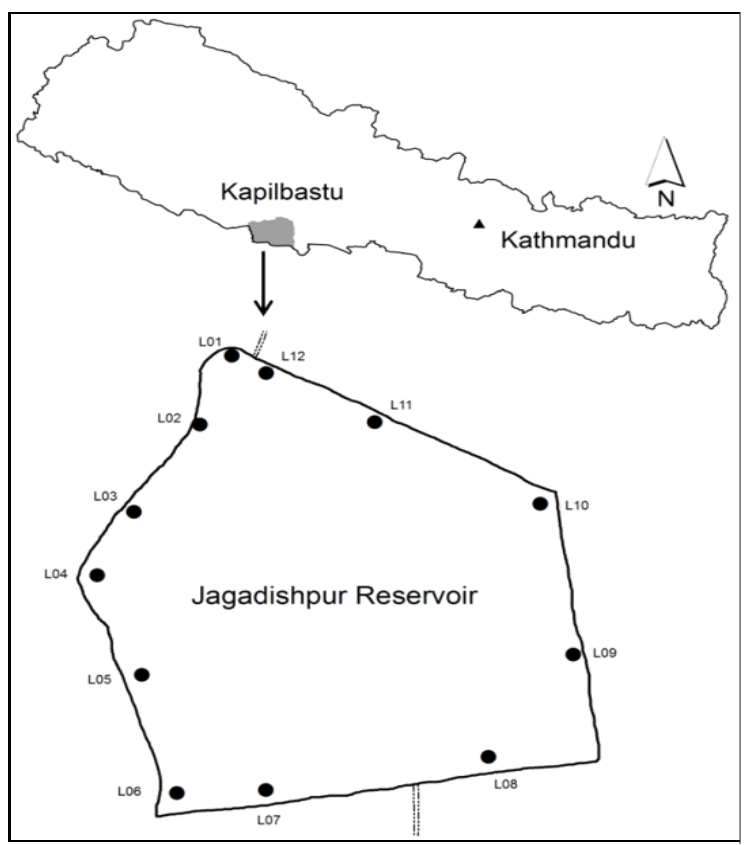

Fig. 1. Jagadishpur reservoir with the location of sampling sites (indicated by filled circles) and site codes

\section{Study design}

The Lentic Ecosystem Field Protocol (LEFP) was developed (Annex I) based on the preliminary survey and literature review (David et al. 1998; Moog \& Sharma 2005). During survey, the sketch of the reservoir including various features such as littoral zone substrate types, bank condition and structure, riparian vegetation, wetland use, inflow and outflow conditions etc, and stressors like fish farming, waste disposal, washing, bathing, open defecation, resource extraction etc were noted down to locate sampling sites evenly along the littoral zone considering all habitat types. In total, twelve sites in littoral zone were selected for BMI samples and environmental variables (Fig. 1).

At each site, substrate composition assessment was performed by manually investigating the substrate having at least $5 \%$ habitat coverage in the sampling transect and estimating the proportion of the following substrate categories (macrophytes, algae, organic debris, clay, silt, sand, gravel and boulder).

\section{BMI sampling, sorting and identification}

We conducted sampling during post-monsoon (November 2008) and pre-monsoon (April 2009) seasons. The selection of sampling dates was dependent on the maximum and minimum water levels and the vegetation development. At each site, BMI were sampled for 5 minutes at $10 \mathrm{~m}$ stretch of littoral zone (extending perpendicular from shore to a maximum depth of $1 \mathrm{~m}$ ) by using a kick-and-sweep method with a standard handnet (mesh size of $500 \mu \mathrm{m}$ ). While sampling, we scoured the bottom to ensure that sedentary animals and associated debris were collected. In addition, we turned over the stones, cobbles and plant parts within the sampling area in order to dislodge and collect animals that were hidden underneath or attached to the bottom.

Samples from different sites of the reservoir were separately preserved in $4 \%$ formaldehyde in field. All the BMI were sorted in the laboratory of Hindu Kush Himalayan Benthological Society (HKH BENSO). Animals were identified to the family or genus level based on available keys (Dudgeon 1999, Nesemann et al. 2007, Nesemann et al. 2011). Identified BMI were preserved in $70 \%$ ethanol.

\section{Water sampling}

We collected water sample from each site at a $10 \mathrm{~cm}$ depth before carrying out BMI sampling. Samples were stored in $500 \mathrm{ml}$ polyethylene jars. The sample containing jars were stored on ice and were kept cool until arriving at the CDES/TU laboratory for the analysis. The samples were analysed within two weeks after collection. 
Dissolved oxygen (DO), temperature, $\mathrm{pH}$, conductivity, free $\mathrm{CO}_{2}$, nitrate-nitrogen, ammoniumnitrogen, ortho-phosphate phosphorus, $\mathrm{Ca}^{++}$ hardness, $\mathrm{Mg}^{++}$hardness, total hardness, total alkalinity and chloride were measured (based on methods APHA 1995, and Trivedy \& Goel 1984) for each site.

\section{Data analysis}

Biological metrics: Alpha diversity (Taxa richness, Shannon diversity index), ETO (Ephemeroptera, Trichoptera and Odonata) taxa, Diptera taxa and composition measures (\% of Diptera taxa, \% of ETO taxa, \% of Diptera individuals, \% of Non-insecta individuals, \% of Mollusca individuals and \% of Oligochaetes and Leeches) were calculated for assessing variability in diversity and community assemblages of BMI in post-monsoon and premonsoon seasons.

Multivariate analyses: Detrended Correspondence Analysis (DCA), Principal Component Analysis (PCA), and Cluster Analysis (CA) were carried out for both seasons separately in PC-ORD 5.16 version (McCune and Mefford 2006). Taxa occurrence in less than $12 \%$ of total sites were excluded from the analysis to avoid down weighting BMI distribution pattern. Density of the taxa were transformed into $\log _{10}(\mathrm{x}+1)$ in prior to the analysis. The logarithmic transformation was used to reduce the effect of absolute density. DCA was initially conducted to calculate the maximum amount of variation in the BMI assemblage data. Based on the length of the gradient, an appropriate ordination technique (PCA) was selected for analyzing relationship between biological data and substrate types. Cluster analysis was performed to describe the similarity among the biological samples, where Sorensen Bray-Curtis was used as distance measures and flexible beta for group linkage method.

Statistical tests were carried out in statistical program SPSS (version 10 for windows; SPSS Inc, Chicago, IL). Non-parametric Spearman correlation test was performed between taxa richness and soft substrates (organic debris, mud/clay and macrophytes) and nonsoft substrates (cobbles, boulders) for both seasons separately. In addition, non-parametric Wilcoxon Signed Ranks Test was conducted for statistical significance difference in biological metrics and environmental variables between post-monsoon and pre-monsoon seasons.

\section{Results and Discussion BMI diversity and assemblages}

In total, fifty families of BMI belonging to fifteen orders were recorded from littoral zone of the reservoir. Forty six families belonging to fourteen orders in postmonsoon and thirty eight families belonging to fifteen orders in pre-monsoon were documented. Higher number of families was recorded from Heteroptera (water bugs), Diptera (flies) and Mollusca for the both seasons (Fig. 2). Mean density of BMI was 260.4 ind./ $\mathrm{m}^{2}$ for post-monsoon and 453.05 ind. $/ \mathrm{m}^{2}$ for premonsoon seasons. Chironomidae density alone occupied $24.6 \%$ and $53.1 \%$ in post-monsoon and premonsoon seasons respectively. Similarly, Mollusca contributed $34.6 \%$ in post-monsoon and $24.6 \%$ in premonsoon while water Bugs contributed only $6.6 \%$ in post-monsoon and $1.2 \%$ in pre-monsoon to the total BMI density.

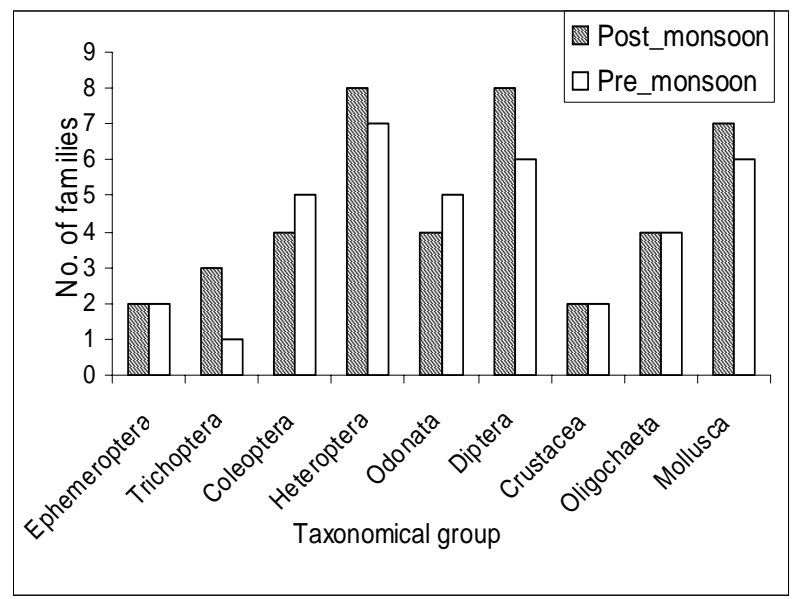

Fig. 2. Comparison of number of families present per taxonomical group in post-monsoon (November 2008) and pre-monsoon (April 2009) seasons.

\section{Biological metrics}

Shannon diversity index (H') was $1.82 \pm 0.46$ in postmonsoon and $1.38 \pm 0.53$ in pre-monsoon and was significantly different between seasons (Wilcoxon Signed Ranks Test $(Z)=-2.196, p=0.03)$ (Fig. 3) while taxa richness (total no. of taxa) $(\mathrm{Z}=-0.747, \mathrm{p}=0.46)$, no. of ETO taxa ( $Z=-0.258, p=0.79)$, no. of Diptera taxa $(Z$ $=-1.75, p=0.08)$, no. of Mollusca taxa $(Z=-1.25, p=0.2)$ were not significantly different between post-monsoon and pre-monsoon seasons ( $\mathrm{n}=12$ for all cases). 
Deep Narayan Shah et al./Diversity and Community

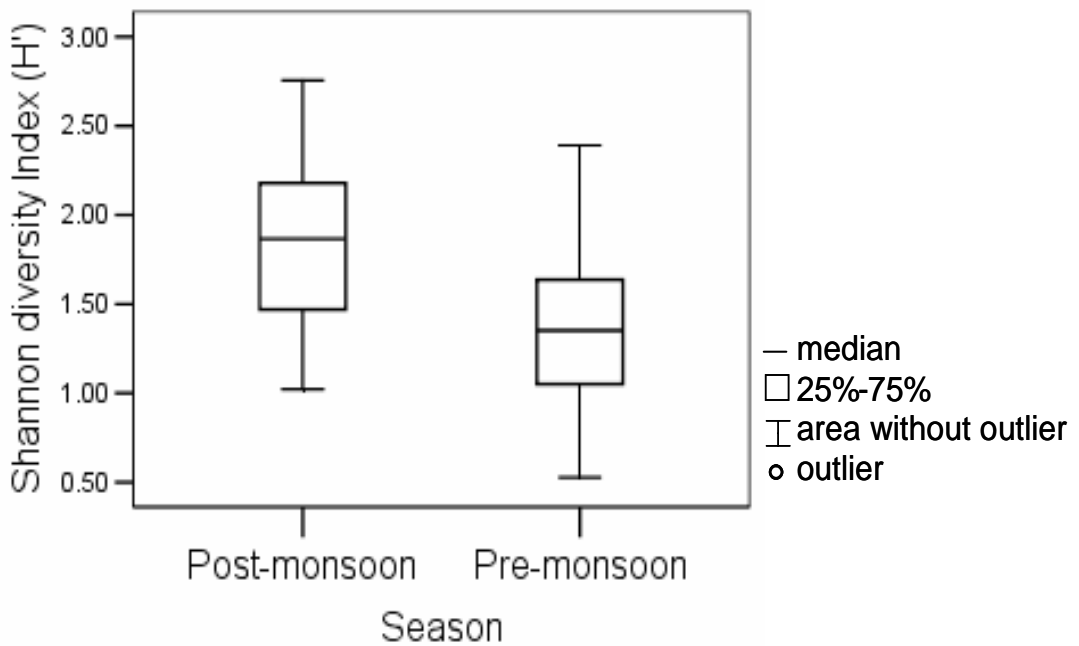

Fig. 3. Box and whisker-plots of Shannon diversity index for post-monsoon (November 2008) and pre-monsoon (April 2009) seasons in Jagadishpur Reservoir.

Composition measures like density $(\mathrm{Z}=-3.059$, $\mathrm{p}=0.002), \%$ of Diptera taxa $(\mathrm{Z}=-2.35, \mathrm{p}=0.02), \%$ of Diptera ind. ( $\mathrm{Z}=-3.059, \mathrm{p}=0.002), \%$ of non-insecta ind. $(Z=-2.59, p=0.01)$ were significantly different between post-monsoon and pre-monsoon (Fig. 4) seasons.
However, \% of ETO taxa ( $\mathrm{Z}=-0.355, \mathrm{p}=0.72)$, \% of Mollusca taxa $(Z=-1.33, p=0.2)$, \% of Oligochaeta and Leeches ind. $(\mathrm{Z}=-0.978, \mathrm{p}=0.32)$ and $\%$ of Mollusca ind. $(\mathrm{Z}=0.182, \mathrm{p}=0.2)$ were not significantly different between seasons ( $\mathrm{n}=12$ sites for all cases).
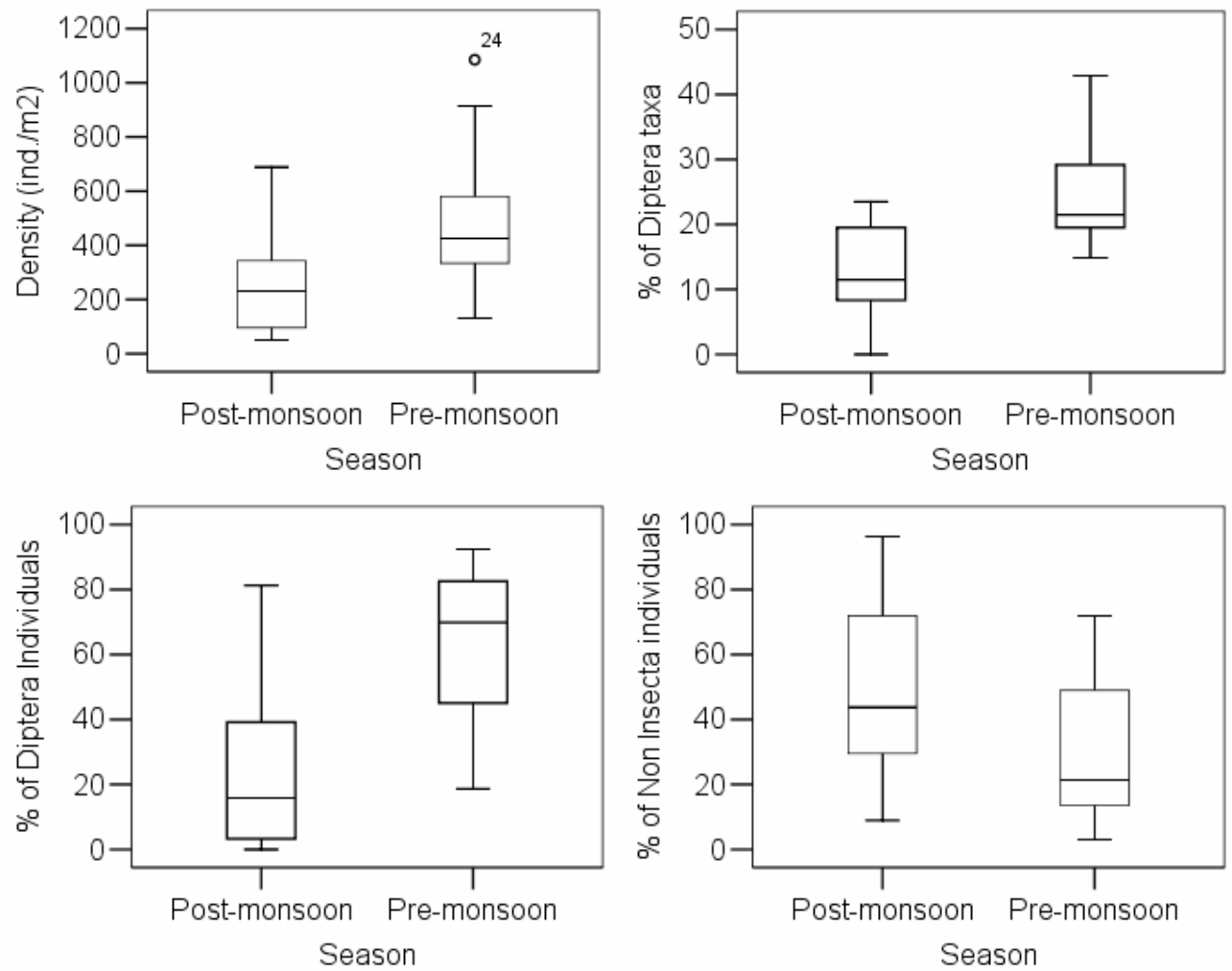

Fig. 4. Box and whisker-plots of composition measures $(\mathrm{n}=12)$ for post-monsoon (November 2008) and pre-monsoon (April 2009) seasons in Jagadishpur Reservoir. 


\section{Physical and chemical attributes}

Temperature, $\mathrm{pH}$, dissolved oxygen, free $\mathrm{CO}_{2}$, total alkalinity, $\mathrm{Ca}^{++}$hardness, $\mathrm{Mg}^{++}$hardness and Orthophosphate phosphorus significantly varied between seasons (Wilcoxon Signed Ranks Test) (Table 1).

Table 1. Physical and chemical variables measured in 12 littoral sites of Jagadishpur Reservoir during the period post-monsoon (November 2008) and premonsoon (April 2009). The symbol -* indicates that the variables are significantly different between seasons (Wilcoxon Signed Ranks Test, $\mathrm{p}<0.05$ ). nitratenitrogen was measured for only one time in postmonsoon (November 2008), thus it is not included in the analysis.

\begin{tabular}{|c|c|c|}
\hline Parameters & $\begin{array}{l}\text { Post-monsoon } \\
\text { (MeantSD) }\end{array}$ & $\begin{array}{l}\text { Premonsoon } \\
\text { (Mleant SD) }\end{array}$ \\
\hline $\begin{array}{l}\text { *Tenquature ( C) } \\
{ }^{*} \mathrm{pH}\end{array}$ & $\begin{array}{l}24 . \pm 1.24 \\
7.72 \pm 0.16\end{array}$ & $\begin{array}{l}31.83 \pm 2.38 \\
8.13 \pm 034\end{array}$ \\
\hline $\begin{array}{l}\text { Conductivity }(\mu \mathrm{S} / \mathrm{cm}) \\
\text { (p=0.4) } \\
\text { *DO (mol) } \\
\text { *Free } \mathrm{CO}_{2}(\mathrm{mg} / \mathrm{l}) \\
\text { *Total alkalinity (mg/) }\end{array}$ & $\begin{array}{l}388.42 \pm 39.59 \\
795 \pm 0.76 \\
26.55 \pm 4.17 \\
293.04 \pm 147.04\end{array}$ & $\begin{array}{l}373.25 \pm 42.87 \\
6.0 \pm 1.2 \\
14.92 \pm 5.72 \\
178.58 \pm 24.22\end{array}$ \\
\hline $\begin{array}{l}\text { * Ca Hardness (mg/l) } \\
\text { * Mg Hardness (mg/l) } \\
\text { Total Hardness (mg/l) }\end{array}$ & $\begin{array}{l}45.29 \pm 6.85 \\
19.65 \pm 2.23\end{array}$ & $\begin{array}{l}28.29 \pm 7.90 \\
32.11 \pm 4.29\end{array}$ \\
\hline $\begin{array}{l}(\mathrm{p}=0.08) \\
\text { Chlonide }(\mathrm{m} / \mathrm{l})\end{array}$ & $19367 \pm 16.42$ & $206.03 \pm 25.72$ \\
\hline$(p=0.86)$ & $23.24 \pm 2.93$ & $23.51 \pm 2.22$ \\
\hline $\begin{array}{l}\text { Nitate-H }(\mathrm{mg} / \mathrm{l}) \\
\text { Ammormim-H }(\mathrm{mg} / \mathrm{l})\end{array}$ & $0305 \pm 0.224$ & ----- \\
\hline $\begin{array}{l}(p=0.47) \\
* O r t h o p h o s p h a t e-P\end{array}$ & $0090 \pm 0.017$ & $0.089 \pm 0.016$ \\
\hline$(\mathrm{mg} / \mathrm{l})$ & $0305 \pm 0.0224$ & $0.563 \pm 0.273$ \\
\hline
\end{tabular}

\section{Community assemblages and environmental variables}

\section{PCA and CA for post-monsoon season}

The first and second PCA axes explained 51.62\% of the variance in littoral BMI data set (Fig 5a). Three axes explained $65.7 \%$ of cumulative variance in species composition. Axis 1 is positively correlated with nonsoft substrate and negatively correlated with soft substrates. Higher taxa richness was recorded at soft substrates (spearman $\mathrm{r}=0.65, \mathrm{p}<0.05$ ) while lower at non-soft substrates (Spearman $r=-0.61, p<0.05$ ) in the reservoir.

The cluster analysis performed on the samples discriminated two main groups, with two sub groups within each group (Figure 5b). The main groups correspond to sample sites with majority of soft and non-soft substrates.
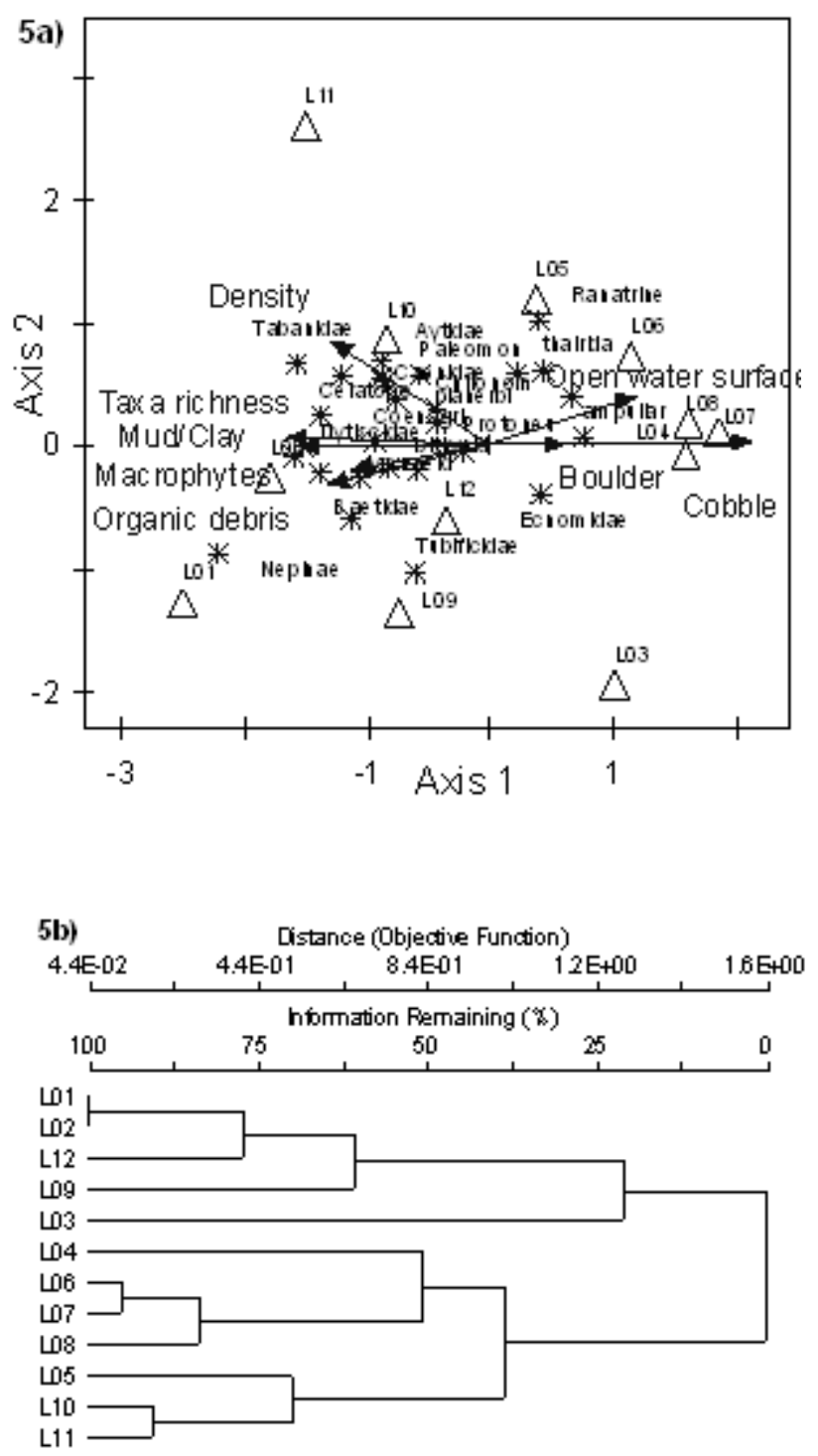

Fig. 5. a) Principal Component Analysis (PCA) biplot showing relationship between BMI data and substrate types. * represents benthic macroinvertebrate taxon, triangle (") indicates sample site $(n=12)$ and vectors represent biological metrics and substrate types. b) Cluster Analysis of sites based on BMI assemblage for post-monsoon (November 2008). Distance measure: Bray-Curtis similarity; linkage method: flexible beta $(=-0.25)$.

\section{PCA and CA for pre-monsoon season}

The first and second PCA axes explained $54.5 \%$ of the variance in littoral BMI data set (Fig 6a). Three axes explained $71.8 \%$ of cumulative variance in species composition. Axis 1 is positively correlated with nonsoft substrate and negatively correlated with soft 
substrates. Higher taxa richness was recorded at soft substrates (spearman $\mathrm{r}=0.66, \mathrm{p}<0.05$ ) and lower at nonsoft substrates (Spearman $r=-0.67, \mathrm{p}<0.05$ ) in the reservoir.

The cluster analysis performed on the samples discriminated two main groups, with two sub groups within each group (Figure 6b). The main groups correspond to sample sites with majority of soft and non-soft substrates.
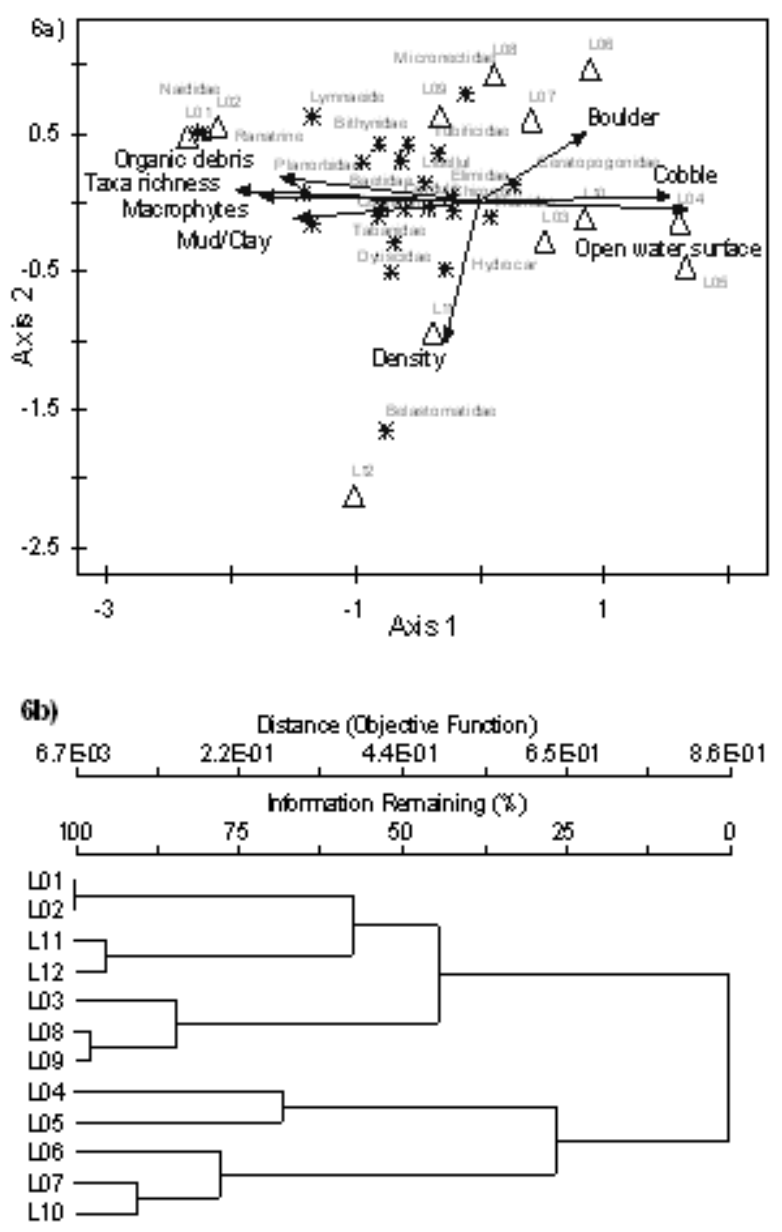

Fig. 6. a) Principal Component Analysis (PCA) biplot showing relationship between BMI data and substrate types. * represents benthic macroinvertebrate taxon, triangle (“) indicates sample site $(\mathrm{n}=12)$ and vectors represent biological metrics and substrate types. b.) Cluster Analysis of sites based on BMI assemblages in pre-monsoon (April 2009). Distance measure: Bray-Curtis similarity; linkage method: flexible beta $(=-0.25)$.

\section{BMI diversity, assemblages and biological metrics}

We recorded slightly higher number of taxa for postmonsoon than pre-monsoon season. This could be due to decreased water level resulting to decreased wetted reservoir surface area and habitat types. In addition, it could also be due to BMI life cycle length, flight time etc. In both seasons, the littoral zone was dominated by Diptera (flies) and Mollusca (particularly gastropods) which in particular are dominant taxonomic groups in low land stagnant water bodies.

The overall mean BMI density was about half in postmonsoon than pre-monsoon season and showed significant difference between the seasons. However, mean BMI densities recorded for both seasons in the reservoir are comparable to other reservoirs like Jinshahe and Daoguanhe, China (Lv et al. 2010) where densities about 300 individuals $/ \mathrm{m}^{2}$ were documented. Mollusca and Diptera contributed high proportion in total densities of BMI for both seasons. However, relatively lower densities of Mollusca in pre-monsoon season might be due to the harvest of snail (Pila globosa, Bellamya bengalensis etc.) by local people for food resource. Among Diptera, higher density of Chironomids was documented for both the seasons which are typical for many freshwater systems (Heatherly and Whiles 2005). Relatively higher density of Chironomidae was recorded in pre-monsoon season, this might be attributed to the presence of soft and fine substrates (Heatherly and Whiles 2005; Weatherhead and James 2001). Also, the fish harvest (January/February 2009) might have reduced predation on BMI (e.g., Solimini et al. 2006) during premonsoon season.

The mean value of diversity index in the reservoir (1.82, post-monsoon and 1.38, pre-monsoon) is an indication of the disturbance in the environmental conditions (Wilhm \& Dorris 1968). The index value is relatively lower for post-monsoon compared to other manmade wetlands like Asan wetland (Sharma \& Rawat 2009). The commercial fish farming with the introduction of exotic species and alteration in substrate composition due to surface water level fluctuation might have strongly influenced the diversity index which is in accordance with other studies (Baxter 1977, Hellsten et al. 1996; Hill \& Keddy 1992). In addition, other anthropogenic utilization (Wetzel 1990) might also be influencing the reservoir's BMI diversity. 


\section{PCA and CA analysis}

The result of PCA showed higher number of BMI taxa at sites dominated with soft substrate habitats than those dominated by cobbles and boulders for both seasons, supporting the studies conducted by Watkins et al. (1983) and Mcewen and Butler (2010).

The similarity in community assemblages of BMI are primarily driven by substrate distribution in littoral zone. For instance, similar substrate habitats in L01 and L02 (inlet side) sites showed almost similar taxa assemblage (family level) for both seasons in the reservoir. The change in substrate types modified BMI assemblages (see Solimini et al. 2006) because substrate is an important factor directly controlling littoral BMI distribution and abundance (e.g. Weatherhead \& James 2001).

We conclude that the diversity and community assemblage of littoral BMI is highly dependent on substrate distribution in the reservoir, i.e., higher numbers of taxa are associated with soft-substrates than non-soft substrates. Therefore, maintaining littoral zone habitat in natural condition will enhance stable BMI assemblage. Our study also foresee that intensive fish farming and surface water level fluctuation could have adversely affected littoral BMI diversity and community assemblage, however, more research are required for better understanding of the mechanism. Sustainable water harvest and low human activities will prevent the loss of littoral habitat and thus maintain benthic macroinvertebrate diversity and assemblage. In turn, this will help to maintain nature conservation interest.

\section{Acknowledgements}

We thank our research team members Mr. Pramod Bhagat, Ms. Mangleshwori Dhonju, Ms. Mira Prajapati and Mrs Manju Sapkota. We also thank Prof. Dr. Subodh Sharma for his technical advice. We are grateful to Dr. Dinesh Raj Bhuju for his advices and encouragement in conducting this research. This research was supported by a grant

\section{References}

APHA, AWWA and WPCF. 1995. Standard methods for examination of water and waste water. Nineteen editions. American Public Health Association, Washington D.C.

Baral, H.M. 2008. Birds of Jagadishpur Reservoir, Nepal. Forktail 24:115-119.
Batzer, D.P., M. McGee, V.H. Resh and R.R. Smith. 1993. Characteristics of invertebrates consumed by mallards and prey response to wetland flooding schedules. Wetlands 13:41-49.

Baxter, R. M. 1977. Environmental effects of dams and impoundments. Annual Review of Ecology, Evolution and Systematics 8:255-283.

Bhuju U.R., P.R. Shakya, T.B. Basnet and S. Shrestha. 2007. Nepal biodiversity resource book: Protected areas, ramsar sites and world heritage sites. International Centre for Integrated Mountain Development (ICIMOD) and Ministry of Environment, Science and Technology (MOEST), Gevernment of Nepal (GoN).

Costanza, R., R. D’Arge, R. Degroot, S. Farber, M. Grasso, B. Hannon, K. Limburg, S. Naeem, R.V. O’Neill, J. Paruelo, R.G. Raskin, P. Sutton and M. Van Den Belt. 1991. The value of the world's ecosystem services and natural capital. Nature 387:253-260.

Dudgeon, D. 1999. Tropical Asian stream: Zoobenthos, ecology and conversation. Hong Kong University Press.

Dudley, T.L. 1988. The roles of plant complexity and epiphyton in colonization of macrophytes by stream insects. Verhandlung International Verein Limnology 23:11531158.

Euliss N.H. and G. Grodhaus. 1987. Management of midges and other invertebrates for waterfowl wintering in California. California Fish and Game 73: 238-243.

Euliss, N.H., R.L Jarvis and D.S. Gilmer. 1991. Feeding ecology of waterfowl wintering on evaporation ponds in California. Condor 93:582-590.

Gautam, B. and B. Bhattarai. 2008. Seasonal changes in water quality parameters and sediment nutrients in Jagadishpur Reservoir, a Ramsar site in Nepal. Nepal Journal of Science and Technology 9: 149-156.

Hellsten, S., M. Marttunen, R. Palomäki, J. Riihimäki and E. Alasaarela.1996. Towards an ecologically-based regulation practice in Finnish hydroelectric lakes. Regulated Rivers: Research and Management 12: 535-545.

Hill, N.M. and P.A. Keddy. 1992. Prediction of rarities from habitat variables: coastal plain plants on

Nova Scotian lakeshores. Ecology 73: 1852-1859.

Lv, G., B. Xiong, M. Liu, X. Yang, L. Qin, P. Chen,W. Xu, J. Liu and K. Wei. 2010. Composition and structure of benthic macroinvertebrate community in two reservoirs in Hubei province, China: Response to eutrophication. Desalination and water treatment 20: 297-306.

Hann, B.J. 1991. Invertebrate grazer-periphyton interactions in a eutrophic marsh pond. Freshwater Biology 26: 87-96.

Heatherly, II T. and M.R. Whiles. 2005. Diversity and community structure of littoral zone macroinvertebrates in Southern Illionis reclaimed surface mines lakes. The American Midland Naturalist Journal 154: 67-77. 
Deep Narayan Shah et al./Diversity and Community ........

Lodge, D.M. 1985. Macrophyte-Gastropod associations: observations and experiments on macrophyte choice by gastropods. Freshwater Biology 15: 695-708.

McCune, B.A. and M.J. Mefford, 2006. PC-ORD. Multivariate Analysis of Ecological Data. Version 5.16. MjM Software, Gleneden Beach, Oregon, U.S.A.

Mcewen, D.C. and M.G. Butler. 2010. The effects of water level manipulation on the benthic invertebrates of a managed reservoir, Freshwater Biology 55: 1086-1101.

Moog, O. and S. Sharma. 2005. http://www.assess-hkh.at/ downloads/HKH_site_protocol_v3_2006-02-22.pdf.

Nesemann, H., S. Sharma, G. Sharma, S. Khanal, B. Pradhan, D.N. Shah, and R.D. Tachamo. 2007. Aquatic invertebrates of the Ganga River System. Vol. 1. Kathmandu, Nepal.

Nesemann, H., R.D.T. Shah, D.N., Shah and S. Sharma. 2011. Key to the larval stages of common Odonata of Hindu Kush Himalaya, with short notes on habitats and ecology. Journal of Threatened Taxa 3: 2045-2060.

Niemi, G.J. and M. McDonald. 2004. Application of ecological indicators. Annual Review of Ecology, Evolution and Systematics 35: 89-111.

Reice, S.R. and M. Wohlenberg. 1993. Monitoring freshwater benthic macroinvertebrates and benthic processes: measures for assessment of ecosystem health. In: Freshwater biomonitoring and benthic macroinvertebrates (Eds. D.M. Rosenberg \& V.H. Resh). Chapman and Hall, New York, Pp.287-305.

Schriver, P., J. Bogestrand, E. Jeppesen and M. Sondergaard. 1995. Impact of submerged macrophytes on fishzooplankton-phytoplankton interactions: large-scale enclosure experiments in a shallow eutrophic lake. Freshwater Biology 33:255-270.

Shah, R.D.T., D.N. Shah and H. Nesemann. 2011. Development of a macroinvertebrate-based Nepal Lake Biotic Index (NLBI): an applied method for assessing the ecological quality of lakes and reservoirs in Nepal. International Journal of Hydrology Science and Technology 1:125-146.

Sharma, R.C. and J.S. Rawat. 2009. Monitoring of aquatic macroinvertebrates as bioindicator for assessing the health of wetlands: A case study in the Central Himalayas, India. Ecological Indicators 9:118-128.
Solimini, A.G., G. Free, I. Donohue, K. Irvine, M. Pusch, B. Rossaro, L. Sandin and C. Ana Cardoso. 2006. Using benthic macroinvertebrates to assess ecological status of lakes current knowledge and way forward to support WFD Implementation. Obtained through the Internet: http://www.igb-berlin.de/. [ accessed 15/09/2010].

Soszka, G.J. 1975. Ecological relationships between invertebrates and submerged macrophytes in the lake littoral. Ekologia Polska 23: 393-415.

Stevenson, R.J. and F.R. Hauer. 2002. Integrating hydrogeomorphic and index of biotic integrity approaches for environmental assessment of wetalnds. Journal of the American Benthological Society 21: $502-513$

Swanson, G.A. 1988. Aquatic habitats of breeding waterfowl. In: The Ecology and Management of Wetlands (Ed. D.L. Hook). Croom Helm, Kent. Pp.195-203.

Trivedy, R.K. and P.K. Goel. 1986. Chemical and biological methods for water pollution studies. Department of Environmental Pollution. Y. K. College of Science, Karad, India.

Watkins, C.E., J.V. Shireman and W.T. Haller. 1983. The influence of aquatic vegetation upon zooplankton and benthic macroinvertebrates in Orange Lake, Florida. Journal of Aquatic Plant Management 21:78-83.

Weatherhead, M.A. and M.R. James. 2001. Distribution of macroinvertebrates in relation to physical and biological variables in the littoral zone of nine New Zealand Lakes. Hydrobiologia 462:115-129.

Wetzel, R.G. 1990. Reservoir ecosystems: Conclusions and speculations. In: Reservoir limnology: Ecological perspectives (Eds K.W. Thornton, B.L. Kimmel \& F.E. Payne). Wiley, New York, Pp.27-38.

Wiley M.J., R.W. Gorden, S.W. Waite and T. Powless. 1984. The relationship between aquatic macrophytes and sport fish production in Illinois ponds: a simple model. North American Journal of Fisheries Management 4:111-119.

Wilhm, J.L. and T.C. Dorris. 1968. Biological parameters of water quality criteria. Bioscience 18: 477-481. 
Nepal Journal of Science and Technology 12 (2011) 211-219 